\title{
ATRIBUTOS FÍSICOS E BALANÇO HÍDRICO DO SOLO COM FLORESTA OMBRÓFILA MISTA, EM LATOSSOLO VERMELHO-AMARELO, EM TELÊMACO BORBA - PR
}

\author{
PHYSICAL ATTRIBUTES AND FIELD WATER BALANCE FOR NATIVE OMBROPHYLOUS \\ FOREST, ON AN OXISOL, IN TELÊMACO BORBA - PR STATE
}

\author{
Jorge Luiz Moretti de Souza ${ }^{1}$ Kharyn Freitas Fezer ${ }^{2}$ Bruno César Gurski ${ }^{3}$ Daniela Jerszurki ${ }^{4}$ \\ Paulo Eugenio Pachechenik ${ }^{5}$ Adão Wagner Pego Evangelista ${ }^{6}$
}

\section{RESUMO}

Objetivou-se no presente trabalho caracterizar os atributos físico-hídricos do solo e quantificar, em um ano, as componentes de um balanço hídrico, realizado para Floresta Ombrófila Mista em Latossolo VermelhoAmarelo, textura arenosa, em Telêmaco Borba - PR. O experimento foi instalado na Fazenda Monte Alegre, pertencente à empresa Klabin Florestal, em área com mata nativa em estado avançado de regeneração. Foram caracterizados os seguintes atributos físicos do solo: massa específica, condutividade hidráulica saturada, curva de retenção da água, porosidade de aeração e capacidade de água disponível $(C A D)$. As amostras indeformadas foram coletadas em uma trincheira, em cinco camadas. As amostras deformadas foram retiradas semanalmente, em oito pontos dentro da área experimental, em cinco camadas. Os valores de umidades do solo e precipitação interna foram coletados e registrados semanalmente ao longo do ano. O armazenamento de água no solo foi calculado empregando a regra do trapézio. A drenagem interna $(D)$ e a ascensão capilar $(A C)$ foram estimadas com a equação de Darcy-Buckingham. Os valores de massa específica, micro, macro e porosidade total do solo enquadraram-se nas faixas consideradas adequadas para solos de textura arenosa. O solo apresentou alta condutividade hidráulica, característica de solos bem drenados. Em média, o armazenamento não atingiu o ponto de murcha permanente ao longo do ano. A $D$ média foi maior nos meses com maior precipitação, sendo o valor total anual médio de $94,9 \mathrm{~mm}$ ano ${ }^{-1}$. O valor médio da evapotranspiração real foi de $1355,9 \mathrm{~mm}^{2} o^{-1}$, média de $3,7 \mathrm{~mm} \mathrm{dia}^{-1}$.

Palavras-chave: floresta nativa, relações hídricas; evapotranspiração.

\section{ABSTRACT}

The objective of this study was to characterize the soil physical and hydric attributes and quantify, in one year, the water balance components, carried out for Native Ombrophylous Forest, in an OXISOL, sandy texture, in Telêmaco Borba - PR state. The experiment was held at Monte Alegre Farm, which belongs to the company Klabin Florestal, the area was under native forest in an advanced state of regeneration. The following physical and hydric attributes were characterized: bulk density, saturated hydraulic conductivity, soil water retention curve, aeration porosity and total available water $(T A W)$. The undisturbed samples were collected in a trench, in five depths. The disturbed samples were collected weekly, in eight different points inside the experiment area, in five depths. The values of soil moisture and internal precipitation were

1 Engenheiro Agrícola, Dr., Professor da Universidade Federal do Paraná, Setor de Ciências Agrárias, Rua dos Funcionários, 1540, CEP 80035-050, Curitiba (PR), Brasil.jmoretti@ufpr.br

2 Engenheira Agrônoma, MSc., Pós-Graduação em Ciência do Solo, Universidade Federal do Paraná, Setor de Ciências Agrárias, Rua dos Funcionários, 1540, CEP 80035-050, Curitiba (PR), Brasil. khafezer@gmail.com

3 Engenheiro Agrônomo, MSc., Doutorando em Ciência do Solo, Universidade Federal do Paraná, Setor de Ciências Agrárias, Rua dos Funcionários, 1540, CEP 80035-050, Curitiba (PR), Brasil. brunogurski@ufpr.br

4 Engenheira Agrônoma, Dra., Pós-Graduação em Ciência do Solo, Universidade Federal do Paraná, Setor de Ciências Agrárias, Rua dos Funcionários, 1540, CEP 80035-050, Curitiba (PR), Brasil. djerszurki@gmail.com

5 Engenheiro Agrônomo, Dr., Pós-Graduação em Ciências Florestais, Universidade Federal do Paraná, Setor de Ciências Agrárias, Rua dos Funcionários, 1540, CEP 80035-050, Curitiba (PR), Brasil. p_pache@uol.com.br

6 Engenheiro Agrícola, Dr., Professor da Universidade Federal de Goiás, Campus II, Rodovia Goiânia, Km 0, CEP 74690-900, Goiânia (GO), Brasil. awpego@bol.com.br

Recebido para publicação em 28/01/2015 e aceito em 5/10/2016

Ci. Fl., v. 28, n. 1, jan.- mar., 2018 
collected and registered throughout the year. The soil water storage was calculated using the trapezoidal rule. The internal drainage and capillary rise were estimated by using the Darcy-Buckingham equation. The values of the bulk density, micro, macro and total porosity of the soil are classified in the range considered adequate for soils with sandy texture. The soil presented a high hydraulic conductivity, which is a characteristic of well drained soils. In average, the storage did not reach the permanent wilting point throughout the year. The average deep drainage was bigger throughout the months with more precipitation, the value being an average of $94.9 \mathrm{~mm}^{-1} \mathrm{year}^{-1}$. The average value of the real evapotranspiration was 1355.9 $\mathrm{mm}$ year ${ }^{-1}$, an average of $3.7 \mathrm{~mm} \mathrm{day}^{-1}$.

Keywords: native forest; hydric relations; evapotranspiration.

\section{INTRODUÇÃO}

A grande concentração da Floresta Ombrófila Mista está localizada sobre o Planalto Meridional do Brasil, nos Estados do Rio Grande do Sul, Santa Catarina e Paraná (AUBRÉVILLE, 1949; KLEIN, 1960; HUECK, 1972). Em contrapartida, estudos envolvendo o levantamento dos atributos físicos, bem como as relações hídricas neste tipo de vegetação são raros (ISERNHAGEN, 2001). Existem poucos trabalhos realizados no Rio Grande do Sul (CESTARO, 1988) e Paraná (SEITZ, 1976), o que é limitante, pois esses dados são úteis para uma série de atividades, inclusive servindo de referência para sistemas agrícolas.

A introdução de sistemas agrícolas em substituição às florestas causa desequilíbrio no ecossistema, modificando os atributos do solo, cuja intensidade varia com a natureza do solo e as condições de clima, uso e manejo adotados (GODEFROY; JACQUIN, 1975; VIANA et al., 2011). O uso intensivo dos solos geralmente promove a deterioração de seus atributos físicos (COOTE; RAMSEY, 1983; MELLONI et al., 2008). Modificações na massa específica e porosidade do solo também podem variar consideravelmente, dependendo da textura, teores de matéria orgânica do solo (CURTIS; POST, 1964; SILVA et al., 2011) e frequência de cultivo (HAJABBASI; JALALIAN; KARIMZADEH, 1997). É importante considerar também, que a qualidade física do solo para o crescimento das plantas é determinada não só pela disponibilidade de água, aeração e temperatura, mas também pela resistência que a matriz do solo oferece à penetração das raízes (HAMBLIN, 1985; LETEY, 1985; ASSIS; LANCAS, 2005).

O balanço hídrico do solo é definido como a contabilização dos fluxos de entrada e saída de água em dado volume de controle, durante determinado intervalo de tempo (REICHARDT; TIMM, 2012). A hidrologia florestal trata do movimento da água em ambientes de floresta e o balanço hídrico nestes ambientes depende da precipitação, interceptação de água pelo dossel, escoamento em profundidade (drenagem interna) e da evapotranspiração (ALMEIDA; SOARES, 2003).

Os remanescentes florestais deste tipo de vegetação são elementos importantes na paisagem, pois desempenham relevante função ambiental, protegendo o solo e cursos de água (PINTO, 2011). Além disso, sua importância se estende às esferas econômica e social, devido à existência de várias espécies de interesse madeireiro e não madeireiro (HIGUCHI et al., 2014). Sendo assim, avaliar os atributos físicos do solo e as relações hídricas é de extrema relevância para entender a dinâmica da Floresta Ombrófila Mista, uma vez que esta apresenta elevada biodiversidade.

Teve-se por objetivo no presente trabalho caracterizar os atributos físico-hídricos do solo e quantificar ao longo de um ano os componentes de um balanço hídrico, realizado em uma Floresta Ombrófila Mista sobre Latossolo Vermelho-Amarelo, textura arenosa, em Telêmaco Borba - PR.

\section{MATERIAL E MÉTODOS}

O experimento foi realizado na Fazenda Monte Alegre, pertencente à empresa Klabin Florestal, localizada em Telêmaco Borba - PR, coordenadas $24^{\circ} 13^{\prime} 19^{\prime \prime} \mathrm{S}, 50^{\circ} 32^{\prime} 33^{\prime}$ "W e $700 \mathrm{~m}$ de altitude. Os dados foram coletados no ano de 2009 (PACHECHENIK, 2010), em uma área de mata nativa em fase avançada de regeneração (Floresta Ombrófila Mista).

O experimento está localizado no Segundo Planalto Paranaense e, segundo a classificação de Köppen, possui clima tipo $\mathrm{Cfa} / \mathrm{Cfb}$, subtropical úmido transicional para temperado propriamente dito, com temperatura média no mês mais frio inferior a $16^{\circ} \mathrm{C}$, ocorrência de geadas e temperatura média no mês mais 
quente acima de $22^{\circ} \mathrm{C}$, apresenta verões quentes (CAVIGLIONE et al., 2000).

O solo foi classificado como Latossolo Vermelho-Amarelo, textura arenosa e relevo suave ondulado (EMBRAPA, 2013). Para a realização do trabalho adotou-se o delineamento experimental em blocos ao acaso, em quatro repetições (parcelas), contendo $625 \mathrm{~m}^{2}$ cada parcela (PACHECHENIK, 2010).

As amostras indeformadas foram coletadas em outubro de 2009, em uma trincheira escavada na área com 1,8 $\mathrm{m}$ de profundidade, 1,5 $\mathrm{m}$ de largura e $3 \mathrm{~m}$ de comprimento. As amostras foram retiradas com auxílio de anéis volumétricos com, aproximadamente, $2,87 \mathrm{~cm}$ de altura por $4,7 \mathrm{~cm}$ de diâmetro (volume de $49,79 \mathrm{~cm}^{3}$ ), no centro das camadas de $0-0,1 ; 0,1-0,2 ; 0,2-0,4 ; 0,4-0,6 ; 0,6-1,0 \mathrm{~m}$, com três repetições em cada camada.

A determinação dos atributos físicos do solo com as amostras indeformadas, massa específica do solo $\left(\rho_{S}\right)$, curva de retenção da água no solo e condutividade hidráulica do solo saturado $\left(K_{0}\right)$ foi realizada conforme os procedimentos da EMBRAPA (2011), sendo: $i$ ) A determinação da $\rho_{S}$ foi realizada com o método do anel volumétrico; ii) Para a determinação das tensões e, consequentemente, da curva de retenção da água do solo, as amostras foram previamente saturadas em laboratório e submetidas ao processo de secagem com tensões de 0,$006 ; 0,01 ; 1,0$ e $1,5 \mathrm{MPa}$, sendo utilizadas para esse processo a mesa de tensão e a câmara de Richards. Considerou-se como capacidade de campo $(\theta c c)$ e ponto de murcha permanentes $\left(\theta_{P M P}\right)$ os valores de umidade obtidos nas tensões de $0,006 \mathrm{MPa}$ e $1,5 \mathrm{MPa}$, respectivamente. A porosidade total foi considerada igual à umidade volumétrica do solo na saturação $\left(\theta_{S}\right)$. Os valores de microporosidade do solo foram considerados iguais aos valores de $\theta c c$. Os valores de macroporos das amostras foram obtidos fazendo a diferença entre a $\theta_{S}$ e a $\theta c c$ (ARAUJO; TORMENA; SILVA, 2004); e, iii) A $K_{0}$ foi determinada com o método do permeâmetro de carga constante, conforme EMBRAPA (2011).

A curva de retenção da água no solo de cada camada foi ajustada aos pontos amostrados (potencial matricial versus umidade volumétrica do solo) com auxílio do modelo proposto por Van Genuchten (1980) e programa Soil Water Retention Curve, desenvolvido por Dourado Neto et al. (2001).

$$
\theta=\theta_{r}+\frac{\left(\theta_{s}-\theta_{r}\right)}{\left(1+\left(\alpha \cdot \psi_{m}\right)^{n}\right)^{b}}
$$

Em que: $\theta$ - umidade volumétrica $\left(\mathrm{m}^{3} \mathrm{~m}^{-3}\right) ; \theta_{r}$ - umidade volumétrica residual $\left(\mathrm{m}^{3} \mathrm{~m}^{-3}\right) ; \theta_{S}$ - umidade volumétrica na saturação $\left(\mathrm{m}^{3} \mathrm{~m}^{-3}\right), \psi_{m}$ - potencial matricial da água no solo (hPa); $\alpha$ - parâmetro empírico de ajuste da curva de retenção $\left(\mathrm{hPa}^{-1}\right), n$ e $m$ - parâmetros empíricos de ajustes (adimensionais).

A partir dos valores de $K_{0}$ e dos parâmetros da equação de Van Genuchten (1980) foram constituídas as equações da condutividade hidráulica do solo não saturado $K(\theta)$, em função da variável $\omega$ (umidade efetiva), com a equação de Mualem (1976). Com as equações para cada camada, foram calculados os valores de $K(\theta)$ médio ao longo do ano, para as cinco camadas analisadas.

$$
K(\theta)=K_{0} \cdot\left(\frac{\theta-\theta_{\mathrm{r}}}{\theta_{S}-\theta_{r}}\right)^{\ell} \cdot\left[1-\left(1-\left(\frac{\theta-\theta_{r}}{\theta_{S}-\theta_{r}}\right)^{\frac{1}{m}}\right)^{m}\right]^{2}
$$

Em que: $K(\theta)$ - condutividade hidráulica não saturada do solo $\left(\mathrm{mm} \mathrm{dia}{ }^{-1}\right) ; K_{0}$ - condutividade hidráulica do solo saturado ( $\left.\mathrm{mm} \mathrm{dia}^{-1}\right) ; \ell-$ parâmetro empírico estimado por Mualem (1976) como sendo aproximadamente igual a 0,5; $m$ - parâmetros de ajuste da equação de Van Genutchen (1980) (adimensional); $\theta$ - umidade volumétrica $\left(\mathrm{m}^{3} \mathrm{~m}^{-3}\right)$; $\theta_{r}$ - umidade volumétrica residual $\left(\mathrm{m}^{3} \mathrm{~m}^{-3}\right) ; \theta_{S}$ - umidade volumétrica na saturação $\left(\mathrm{m}^{3} \mathrm{~m}^{-3}\right)$.

Amostras deformadas de solo foram retiradas semanalmente ao longo do ano de 2009, com auxílio do trado holandês, em oito pontos dentro da área experimental, nas camadas $0-0,1 ; 0,1-0,2 ; 0,2-0,4 ; 0,4-0,6$; 0,6-1,0 m. A umidade gravimétrica $(U)$ das amostras foram determinadas conforme os procedimentos da EMBRAPA (2011). A umidade volumétrica $(\theta)$ de cada amostra foi determinada com a expressão:

$$
\theta=\frac{U \cdot \rho_{s}}{\rho_{a}}
$$


Em que: $\theta$ - umidade volumétrica $\left(\mathrm{m}^{3} \mathrm{~m}^{-3}\right) ; U$ - umidade gravimétrica $\left(\mathrm{kg} \mathrm{kg}^{-1}\right) ; \rho_{s}$ - massa específica do solo $\left(\mathrm{kg} \mathrm{m}^{-3}\right)$; $\rho_{a}$ - massa específica da água $\left(\mathrm{kg} \mathrm{m}^{-3}\right)$, considerada igual $1000 \mathrm{~kg} \mathrm{~m}^{-3}$.

A porosidade de aeração $(\beta)$ foi determinada com a expressão:

$$
\beta=(\alpha-\theta)
$$

Em que: $\alpha$-porosidade total $\left(\mathrm{m}^{3} \mathrm{~m}^{-3}\right) ; \beta$ - porosidade de aeração $\left(\mathrm{m}^{3} \mathrm{~m}^{-3}\right) ; \theta$ - umidade volumétrica $\left(\mathrm{m}^{3} \mathrm{~m}^{-3}\right)$.

A evapotranspiração real $(E R)$ foi calculada a partir de um balanço hídrico do solo considerando apenas os fluxos verticais:

$$
E R=-\Delta A_{L}+P-D+A C
$$

Em que: $E R$ - evapotranspiração real $\left(\mathrm{mm}\right.$ período $\left.{ }^{-1}\right) ; \Delta A_{L}$ - variação do armazenamento de água no solo (mm

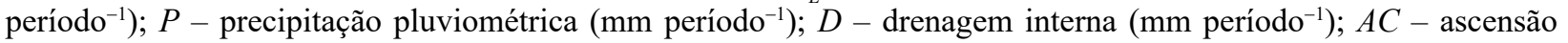
capilar $\left(\mathrm{mm}_{\text { período }}{ }^{-1}\right)$.

O armazenamento de água no solo $\left(A_{L}\right)$ foi calculado empregando a regra do trapézio:

$$
A_{L j}=\theta_{1} \cdot z_{1}+\sum_{i=1}^{n} \frac{\left(\theta_{i}+\theta_{i+1}\right) \cdot z_{i}}{2}
$$

Em que: $A_{L j}$ - armazenamento da água no solo na $j$-ésima semana do ano $(\mathrm{mm}) ; \theta_{i}-$ umidade volumétrica na $i$-ésima camada do solo $\left(\mathrm{cm}^{3} \mathrm{~cm}^{-3}\right) ; z_{i}-i$-ésima camada do solo $(\mathrm{mm}) ; j-$ semanas ao longo do ano em que as amostras foram retiradas (52 semanas); $i$ - camada de coleta das amostras, sendo: 1: 0-0,1, 2: 0,1-0,2, 3: 0,2-0,4, 4: 0,4-0,6, 5: 0,6-1,0 $\mathrm{m}$.

Os valores de precipitação pluvial $\left(P, \mathrm{~mm} \mathrm{dia}^{-1}\right)$ foram medidos com pluviômetros instalados dentro e fora da unidade experimental, sendo oito pluviômetros de acrílico, com capacidade de $40 \mathrm{~mm}$, marca Incotherm.

As componentes drenagem interna $(D)$ e ascensão capilar $(A C)$ foram estimadas por meio do fluxo de água no solo $\left(q_{z}\right)$, utilizando a equação de Darcy-Buckingham (REICHARDT e TIMM, 2012):

$$
q_{z}=-K(\theta) \frac{\partial H}{\partial z}
$$

Em que: $q_{z}$ - fluxo de água no solo para a camada considerada $\left(\mathrm{mm} \mathrm{dia}^{-1}\right) ; K(\theta)$ - condutividade hidráulica não saturada do solo $\left(\mathrm{mm} \mathrm{dia}^{-1}\right) ; \partial H / \partial z$ - gradiente de potencial total $\left(\mathrm{m} \mathrm{m}^{-1}\right) ; z$ - camada do solo $(\mathrm{m})$.

Para o cálculo da capacidade de água disponível foi utilizada a expressão:

$$
C A D=\sum_{i=i}^{n}\left(\theta_{C C i}-\theta_{P M P i}\right) \cdot z_{i}
$$

Em que: $C A D$ - capacidade de água disponível no solo $(\mathrm{mm}) ; \theta_{C C i}$ - umidade volumétrica do solo na capacidade de campo, na $i$-ésima camada $\left(\mathrm{m}^{3} \mathrm{~m}^{-3}\right) ; \theta_{P M P i}$ - umidade volumétrica do solo no ponto de murcha permanente, na $i$-ésima camada $\left(\mathrm{m}^{3} \mathrm{~m}^{-3}\right) ; z_{i}-i$-ésima camada do solo $(\mathrm{mm}) ; n$ - número de camadas no perfil de solo considerado.

Os dados dos atributos físicos do solo foram organizados, agrupados e analisados em planilha eletrônica. Com exceção da condutividade hidráulica, devido à grande variabilidade, realizou-se análise de variância (ANOVA) e teste de Tukey (5\%) de comparação de médias para os demais atributos físicos do solo. 


\section{RESULTADOS E DISCUSSÃO}

Os valores de massa específica do solo $\left(\rho_{S}\right)$ obtidos no experimento ficaram entre 1033 a $1422 \mathrm{~kg}$ $\mathrm{m}^{-3}$. Das cinco camadas avaliadas, apenas a camada de 0,6-1,0 m ficou entre 1400 a $1800 \mathrm{~kg} \mathrm{~m}^{-3}$, faixa mencionada por Reichardt e Timm (2012) como característica para solos de textura arenosa (Tabela 1).

TABELA 1: Massa específica do solo $\left(\rho_{S}\right)$, porosidade total $(\alpha)$, macroporosidade, microporosidade e condutividade hidráulica do solo saturado $\left(K_{0}\right)$ de um Latossolo Vermelho-Amarelo em mata nativa (Floresta Ombrófila Mista), em Telêmaco Borba - PR.

TABLE 1: Bulk density $\left(\rho_{S}\right)$, total porosity $(\alpha)$, macroporosity, microporosity and saturated hydraulic conductivity of soil $\left(K_{0}\right)$, in an Oxisol under native forest (Native Ombrophylous Forest), in Telêmaco Borba - PR state.

\begin{tabular}{cccccc}
\hline $\begin{array}{c}\text { Camada } \\
(\mathrm{m})\end{array}$ & $\begin{array}{c}\rho_{s} \\
\left(\mathrm{~kg} \mathrm{~m}^{-3}\right)\end{array}$ & Macroporos & $\begin{array}{c}\text { Microporos } \\
\left(\mathrm{m}^{3} \mathrm{~m}^{-3}\right)\end{array}$ & $\alpha$ & $\begin{array}{c}K_{0} \\
\left(\mathrm{~mm} \mathrm{dia}^{-1}\right)\end{array}$ \\
\hline $0-0,1$ & $1033 \mathrm{c}$ & $0,394 \mathrm{a}$ & $0,231 \mathrm{c}$ & $0,625 \mathrm{a}$ & 24356,3 \\
$0,1-0,2$ & $1190 \mathrm{bc}$ & $0,307 \mathrm{~b}$ & $0,265 \mathrm{~b}$ & $0,572 \mathrm{~b}$ & 11654,1 \\
$0,2-0,4$ & $1243 \mathrm{abc}$ & $0,260 \mathrm{~b}$ & $0,261 \mathrm{~b}$ & $0,521 \mathrm{c}$ & 9568,5 \\
$0,4-0,6$ & $1322 \mathrm{ab}$ & $0,259 \mathrm{~b}$ & $0,238 \mathrm{bc}$ & $0,498 \mathrm{~cd}$ & 7495,5 \\
$0,6-1,0$ & $1425 \mathrm{a}$ & $0,162 \mathrm{~b} \mathrm{c}$ & $0,302 \mathrm{a}$ & $0,463 \mathrm{~d}$ & 2761,2 \\
\hline $\mathrm{CV}(\%)$ & 11,82 & 30,50 & 10,75 & 11,88 & 72,32 \\
\hline
\end{tabular}

Em que: $\mathrm{CV}=$ Coeficiente de variação. Médias seguidas de letras iguais na coluna não diferem entre si pelo teste de Tukey $(\mathrm{p}<0,05)$.

Os menores valores de massa específica ocorreram na camada $0,0-0,1 \mathrm{~m}$, provavelmente, devido à maior quantidade de raízes (BRUN, 2008), aumentando a $\alpha$. Conforme se verifica em ambientes naturais preservados, observou-se aumento da $\rho_{S}$ somente com o aumento da profundidade, o que evidenciou que o solo está bem conservado e sem compactação (KIEHL, 1979; PREVEDELLO, 1996; REICHARDT; TIMM, 2012). Dedecek et al. (2008) comentam que a maior $\rho_{S}$ em profundidade ocorre devido ao peso do solo das camadas superiores. A $\alpha$ teve a tendência decrescente desde a superfície até a camada mais profunda de $1,0 \mathrm{~m}$.

A macroporosidade do solo variou de 0,162 a $0,394 \mathrm{~m}^{3} \mathrm{~m}^{-3}$ (Tabela 1), sendo que os maiores valores foram encontrados nas camadas superficiais, possivelmente devido à maior atividade da fauna edáfica $\mathrm{e}$ quantidade e diversidade de raízes. A microporosidade variou menos, de 0,231 a $0,302 \mathrm{~m}^{3} \mathrm{~m}^{-3}$, apresentando maiores valores com o aumento da profundidade. Em solos com textura arenosa, há tendência dos valores de macroporosidade serem maiores que de microporosidade. Logo, o solo estudado apresentou tendência, conforme observado por Kiehl (1979) e Reichardt e Timm (2012).

A $\alpha$ corresponde ao espaço disponível para a presença de gases e líquidos no solo. No solo estudado verificaram-se valores entre 46,3 e $62,5 \%$ (Tabela 1 ), sendo que das cinco camadas estudadas, apenas três $(0,2-0,4,0,4-0,6$ e 0,6-1,0 m) se enquadraram na faixa considerada adequada por Kiehl (1979). Para Silva et al. (2005), a maior $\alpha$ na superfície em relação à subsuperfície deve-se aos ciclos sucessivos de umedecimento e secagem que ocorrem na superfície do solo, aliado à melhoria pela maior atividade biológica e acúmulo de matéria orgânica.

A condutividade hidráulica do solo saturado $\left(K_{0}\right)$ teve valor alto (Tabela 1), provavelmente devido à alta porosidade e macroporosidade característica de solos arenosos (REICHARDT; TIMM, 2012). Houve tendência à redução da $K_{0}$ com o aumento da profundidade do perfil, o que também foi evidenciado por Silva et al. (2008), Dalbianco (2009) e Mori (2009). Nas camadas superficiais, a maior permeabilidade em superfície geralmente está relacionada com a maior quantidade de matéria orgânica (CAVICHIOLO, 2005).

De forma geral, a camada de $0-0,1 \mathrm{~m}$ apresentou os maiores valores médios de porosidade de aeração ( $\beta$ ) ao longo do ano (Figura 1), assim como as camadas de 0,4-0,6 e 0,6-1,0 m apresentaram os menores valores ao longo do ano. A maior $\beta$ nas camadas superficiais justifica-se pela presença do sistema radicular das plantas, proporcionando maior aeração à estruturação ao solo. As camadas 0,1-0,2 e 0,2-0,4 m 
apresentaram valores médios de $\beta$ muito próximos (Figura 1 e Tabela 2).

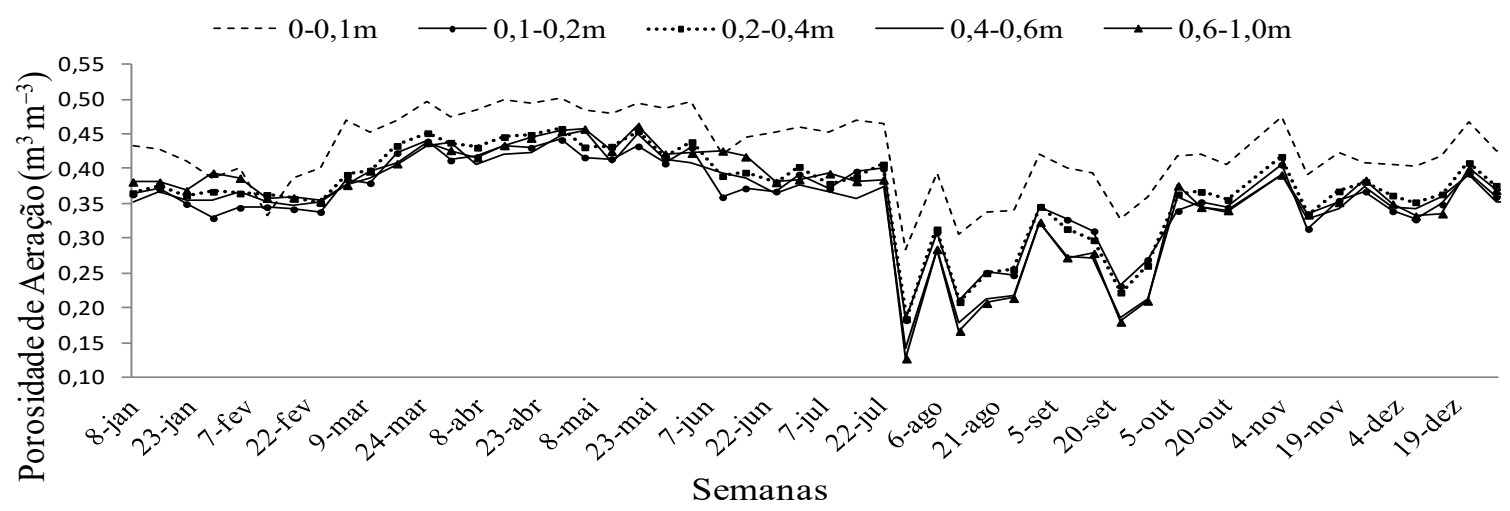

FIGURA 1: Porosidade de aeração de um Latossolo Vermelho-Amarelo, ao longo do ano, sob mata nativa (Floresta Ombrófila Mista), nas camadas $0-0,1 ; 0,1-0,2 ; 0,2-0,4 ; 0,4-0,6$ e $0,6-1,0 \mathrm{~m}$.

FIGURE 1: Aeration porosity of an Oxisol, throughout the year, under native forest (Native Ombrophylous Forest), in the depths $0-0,1 ; 0,1-0,2 ; 0,2-0,4 ; 0,4-0,6$ and $0,6-1,0 \mathrm{~m}$.

No entanto, alguns períodos do ano apresentaram valores de $\beta$ abaixo do ideal $\left(0,25 \mathrm{~m}^{3} \mathrm{~m}^{-3}\right)$, conforme considerado por Reichardt e Timm (2012), principalmente nos meses de julho a setembro. Cabe ressaltar que os limites ideais não estão bem definidos na literatura. Erickson (1982) considera necessário no mínimo $0,10 \mathrm{~m}^{3} \mathrm{~m}^{-3}$ de poros de aeração para a maioria das plantas. Valores abaixo de $0,10 \mathrm{~m}^{3} \mathrm{~m}^{-3}$ não foram atingidos no período estudado, indicando que, provavelmente, as plantas nativas não sofreram limitações quanto à aeração, mas que ficou próxima, principalmente nos meses que mais choveram no ano estudado.

A média da $\beta$ nas estações do ano variou entre 0,287 (camada 0,4-0,6 m; inverno) e 0,481 (camada de 0-0,1 m; outono) (Tabela 2). No ano analisado, o outono caracterizou a estação mais seca.

Independentemente da estação do ano, a camada que apresentou maior $\beta$ foi a $0,1 \mathrm{~m}$, com valores variando de 0,399 a $0,481 \mathrm{~m}^{3} \mathrm{~m}^{-3}$ (Figura 1), sendo essa a camada com menor massa específica e maior macroporosidade do solo (Tabela 1).

TABELA 2: Média da porosidade de aeração do solo, nas diferentes estações do ano e profundidades, em Latossolo Vermelho-Amarelo sob mata nativa (Floresta Ombrófila Mista), em Telêmaco Borba - PR.

TABLE 2: Average soil aeration porosity, in different seasons and depths, in an Oxisol under native forest (Native Ombrophylous Forest), in Telêmaco Borba - PR state.

\begin{tabular}{c|cccc}
\hline \multirow{2}{*}{$\begin{array}{c}\text { Camada } \\
\text { (m) }\end{array}$} & \multicolumn{4}{|c}{ Valor médio da porosidade de aeração do solo nas estações do ano } \\
Verão & Outono & Inverno & Primavera \\
\hline $0-0,10$ & $0,420 \mathrm{a}$ & $0,481 \mathrm{a}$ & $0,399 \mathrm{a}$ & $0,411 \mathrm{a}$ \\
$0,1-0,20$ & $0,363 \mathrm{c}$ & $0,416 \mathrm{c}$ & $0,316 \mathrm{~b}$ & $0,340 \mathrm{bc}$ \\
$0,2-0,40$ & $0,378 \mathrm{bc}$ & $0,433 \mathrm{~b}$ & $0,317 \mathrm{~b}$ & $0,352 \mathrm{~b}$ \\
$0,4-0,60$ & $0,366 \mathrm{bc}$ & $0,422 \mathrm{bc}$ & $0,287 \mathrm{c}$ & $0,331 \mathrm{c}$ \\
$0,6-1,00$ & $0,379 \mathrm{~b}$ & $0,434 \mathrm{~b}$ & $0,292 \mathrm{c}$ & $0,336 \mathrm{bc}$ \\
$\mathrm{CV}(\%)$ & 5,59 & 5,86 & 13,98 & 9,26 \\
\hline
\end{tabular}

Em que: $\mathrm{CV}=$ Coeficiente de variação. Médias seguidas de letras iguais na coluna não diferem entre si pelo teste de Tukey $(\mathrm{p}<0,05)$.

O solo da área experimental apresentou baixa capacidade de retenção de água, devido ao baixo 
teor de argila (14,1\% em média). Por isso, também apresentou pouca quantidade de água retida entre a capacidade de campo $(0,006 \mathrm{MPa})$ e ponto de murcha permanente (1,5 MPa) (Tabela 3$)$.

TABELA 3: Umidade volumétrica da capacidade de campo $\left(\theta_{C C}\right)$, ponto de murcha permanente $\left(\theta_{P M P}\right)$ e parâmetros da equação de Van Genuchten (1980), obtidos do ajustamento da curva com os pontos de retenção de água no solo, amostrado na área contendo mata nativa (Floresta Ombrófila Mista), em Telêmaco Borba - PR.

TABLE 3: Water content of field capacity $\left(\theta_{C C}\right)$, permanent wilting point $\left(\theta_{P M P}\right)$ and parameters of Van Genuchten (1980) equation, obtained from the curve fit with the soil water retention points, sampled in the area containing native forest (Native Ombrophylous Forest), in Telêmaco Borba - PR state.

\begin{tabular}{cccccccc}
\hline $\begin{array}{c}\text { Camada } \\
(\mathrm{m})\end{array}$ & $\theta_{C C}$ & $\theta_{P M P}$ & $\alpha$ & $m$ & $n$ & $\theta r$ & $\theta_{S}$ \\
\hline $0-0,1$ & 0,231 & 0,068 & 1,751 & 0,169 & 1,204 & 0,010 & 0,625 \\
$0,1-0,2$ & 0,265 & 0,063 & 0,379 & 0,175 & 1,211 & 0,006 & 0,572 \\
$0,2-0,4$ & 0,261 & 0,077 & 0,363 & 0,169 & 1,203 & 0,009 & 0,521 \\
$0,4-0,6$ & 0,238 & 0,054 & 0,297 & 0,191 & 1,236 & 0,009 & 0,498 \\
$0,6-1,0$ & 0,302 & 0,066 & 0,091 & 0,202 & 1,254 & 0,009 & 0,463 \\
\hline
\end{tabular}

Em que: $\alpha ; m ; n ; \theta r=$ Parâmetros empíricos da equação de Van Genuchten (1980); $\theta r=$ Conteúdo residual de água do solo $\left(\mathrm{m}^{3} \mathrm{~m}^{-3}\right) ; \theta_{S}=$ Conteúdo de água na condição de solo saturado $\left(\mathrm{m}^{3} \mathrm{~m}^{-3}\right)$.

O traçado das curvas de retenção de água no solo demostrou que o solo estudado está sem sinais de compactação (Figura 2).

O maior conteúdo volumétrico de água disponível no solo $\left(\theta_{\text {disp }}=\theta_{C C}-\theta_{P M P}\right)$ foi verificada na camada de 0,6-1,0 m, em média $0,236 \mathrm{~m}^{3} \mathrm{~m}^{-3}$. Nas camadas de $0-0,1 ; 0,1-0,2 ; 0,2-0,4 ; 0,4-0,6$ e $0,6-1,0 \mathrm{~m}$, os valores ficaram estatisticamente próximos, sendo em média 0,$163 ; 0,202 ; 0,184 ; 0,184$ e $0,236 \mathrm{~m}^{3} \mathrm{~m}^{-3}$, respectivamente (Figura 3). Os resultados confirmam as considerações de Pachechenik (2010), quando em análise preliminar verificou maior teor de argila na camada de 0,6-1,0 m. A maior quantidade de argila nessa profundidade reflete maior quantidade de microporosidade (Tabela 1) e, consequentemente, maior retenção de água na camada.

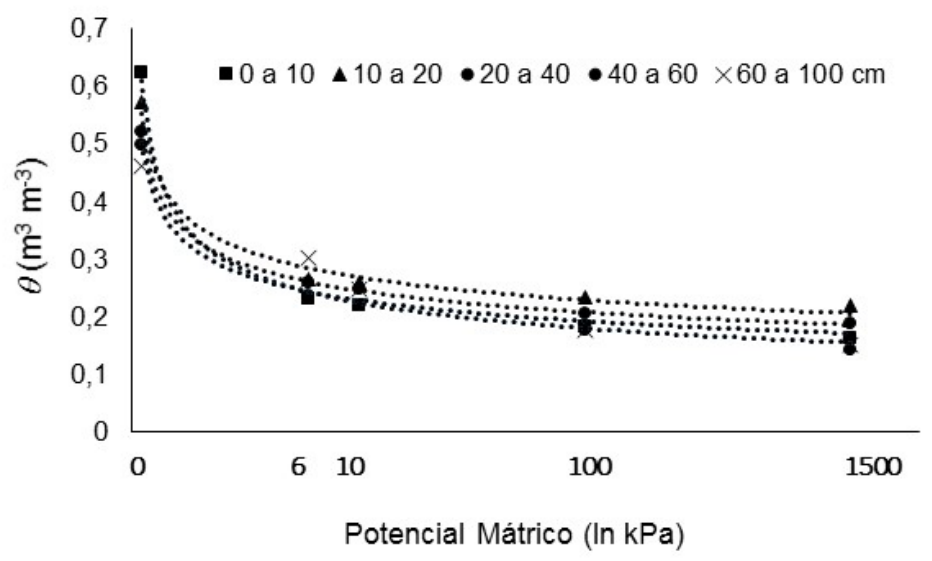

FIGURA 2: Curva de retenção da água em um Latossolo Vermelho-Amarelo, sob mata nativa (Floresta Ombrófila Mista), em Telêmaco Borba - PR, em diferentes camadas.

FIGURE 2: Water retention curve in an Oxisol, under native forest (Native Ombrophylous Forest), in Telêmaco Borba - PR state, under different layers. 


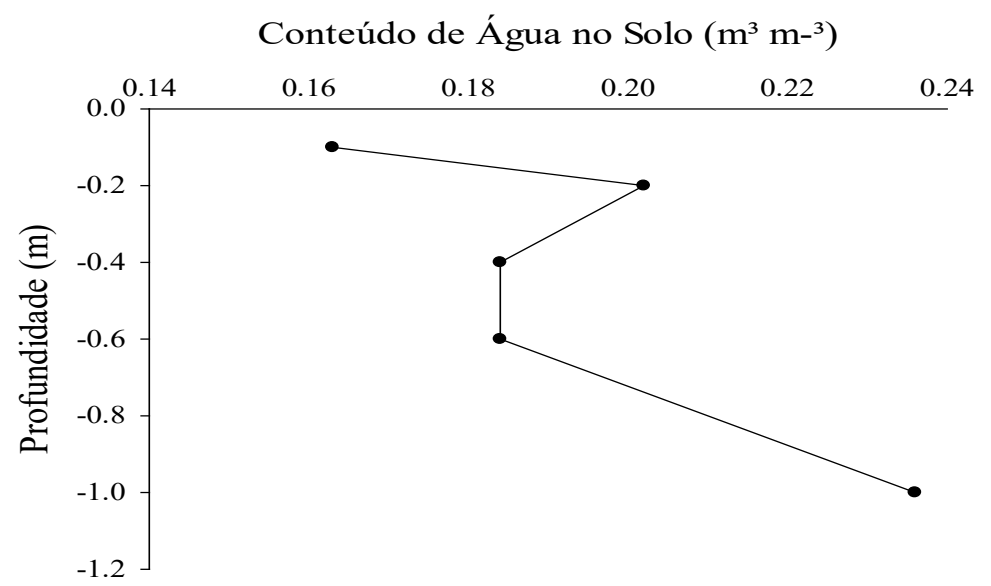

FIGURA 3: Água disponível no solo $\left(\theta_{\text {disp }}=\theta_{C C}-\theta_{P M P}\right)$, em um Latossolo Vermelho-Amarelo, sob Mata Nativa, em Telêmaco Borba - PR.

FIGURE 3: Available soil water $\left(\theta_{\text {disp }}=\theta_{C C}-\theta_{P M P}\right)$ in an Oxisol, under Native Forest, in Telêmaco Borba - PR.

Os valores de capacidade de água diponivel $(C A D)$ calculados para o solo foram de 16,$3 ; 20,2 ; 36,8$; 36,8 e $94,4 \mathrm{~mm}$, para as camada de $0-0,1 ; 0,1-0,2 ; 0,2-0,4 ; 0,4-0,6$ e $0,6-1,0 \mathrm{~m}$, respectivamente. Assim, a $C A D$ para a camada de $1,0 \mathrm{~m}$ foi de $204,5 \mathrm{~mm}$. Os valores encontrados estão de acordo com os obtidos em outros trabalhos, contendo Latossolos com texturas arenosa: Cavalcante e Prado (2010) encontraram CAD média de $45 \mathrm{~mm}$ até $0,40 \mathrm{~m}$ de profundidade em Araxá - MG; Portugal, Costa e Costa (2010), em estudo realizado em Latossolo Vermelho-Amarelo na Zona da Mata, Minas Gerais, encontraram CAD de 15,2 mm na camada de 0-0,20 m em solo sob mata nativa, 20,6 mm para solo cultivado com laranja e 31,4 $\mathrm{mm}$ para solo contendo pasto.

Em relação ao balanço hídrico do solo, a precipitação $(P)$ ocorrida na área experimental durante o período estudado caracterizou-se pela ocorrência de chuvas bem distribuídas (Figura 4), totalizando $1615 \mathrm{~mm}$ ano $^{-1}$. A grande concentração da Floresta Ombrófila Mista está delimitada por precipitações pluviométricas entre 1400 e $2200 \mathrm{~mm} \mathrm{ano}^{-1}$, distribuídas sem ocorrência de estação seca (BACKES, 1999). Historicamente, janeiro é o mês mais chuvoso na região de Telêmaco Borba - PR, no entanto, verificou-se que a maior precipitação interna (experimento) na mata nativa ocorreu em julho $(231,0 \mathrm{~mm})$, seguida por dezembro (202,0 mm) e outubro (191,0 mm).

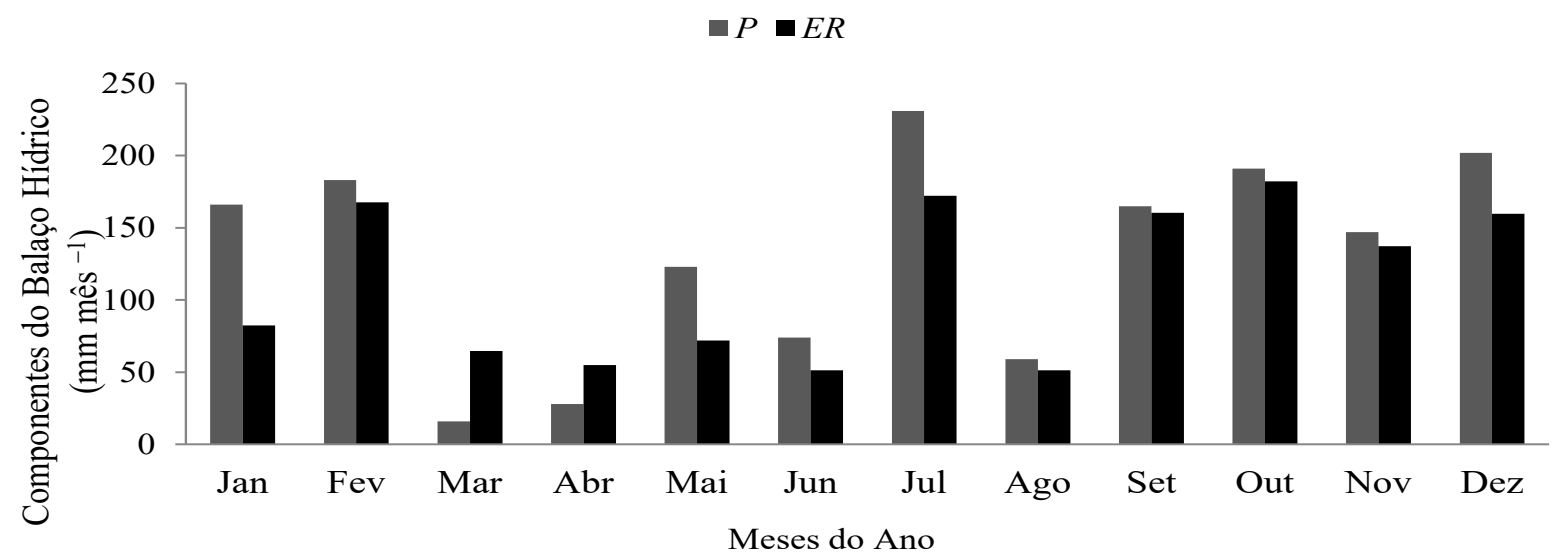

FIGURA 4: Precipitação $(P)$ e evapotranspiração real $(E R)$ verificada na área de Floresta Nativa entre janeiro e dezembro de 2009, em Telêmaco Borba - PR.

FIGURE 4: Precipitation $(P)$ and real evapotranspiration $(E R)$ observed in the Native Forest area between January and December 2009, in Telêmaco Borba - PR state. 
Os maiores valores de evapotranspiração real $(E R)$ ocorreram nos meses de fevereiro $(167,5 \mathrm{~mm}$ mês $\left.{ }^{-1}\right)$, julho (172,2 $\mathrm{mm}$ mês $\left.{ }^{-1}\right)$, setembro $\left(160,4 \mathrm{~mm}\right.$ mês $\left.^{-1}\right)$, outubro $\left(182,2 \mathrm{~mm}\right.$ mês $\left.^{-1}\right)$ e dezembro $\left(159,7 \mathrm{~mm} \mathrm{mês}^{-1}\right)$, sendo que, nestes meses, também ocorreram os maiores valores de $P$ (Figura 4). Soares, Almeida e Penchel (1997) realizando o balanço hídrico para espécies arbóreas verificaram que a condutância estomática e o potencial hídrico foliar diminuíram quando a quantidade de água do solo é reduzida e, consequentemente, a transpiração também. Por outro lado, em condições de alta disponibilidade de água no solo e de radiação líquida, aparentemente o controle estomático não é exercido, ou seja, a planta se autorregula conforme a disponibilidade hídrica. Esse fato pode explicar o aumento da $E R$ nos meses em que ocorreu maior $P$ ao longo do ano (Figura 4). O valor total anual de $E R$ foi $1355,9 \mathrm{~mm} \mathrm{ano}^{-1}$, média de $3,7 \mathrm{~mm} \mathrm{dia}^{-1}$.

$\mathrm{O}$ armazenamento de água no solo $\left(A_{L}\right)$ considerando as umidades na capacidade de campo ficou em torno de 270,2 $\mathrm{mm}$. Ao longo do ano estudado, somente os meses de agosto $\left(312,2 \mathrm{~mm} \mathrm{mês}{ }^{-1}\right)$ e setembro (301,5 mm mês ${ }^{-1}$ ) ficaram acima do valor de $A_{L}$ da capacidade de campo, devido, provavelmente, aos dias chuvosos que antecederam as coletas de amostra de solo para análise de umidade (Figura 5). O $A_{L}$ médio considerando as umidades no ponto de murcha permanente ficou em torno de $65,5 \mathrm{~mm}$, e nenhum dos meses do ano atingiu esse armazenamento de água no solo.

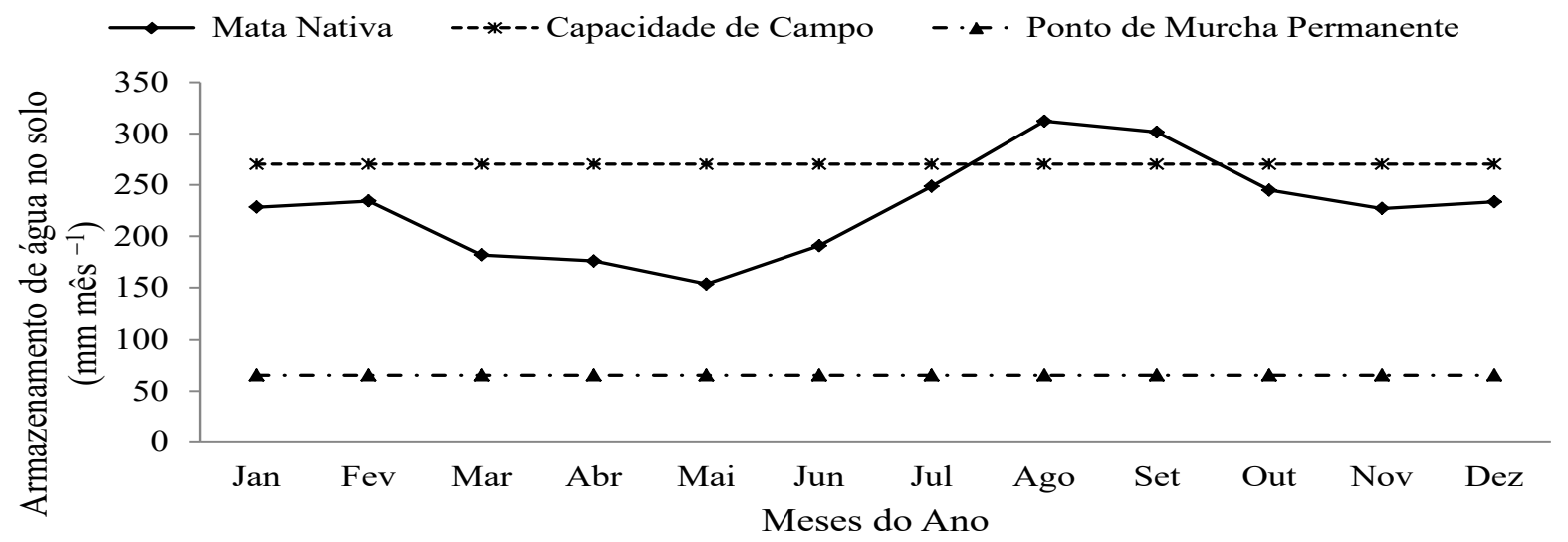

FIGURA 5: Armazenamento médio mensal de água em um Latossolo Vermelho-Amarelo sob Floresta Nativa, ao longo do ano de 2009, em Telêmaco Borba - PR.

FIGURE 5: Average monthly storage of water in an Oxisol under Native Forest, during the year 2009, in Telêmaco Borba - PR state.

As variações do armazenamento de água no solo $\left(\Delta A_{L}\right)$ no perfil do solo acompanharam as variações da precipitação (Figuras 4 e 6), conforme verificado também por Antonino et al. (2000) e Lima et al. (2006). Ocorreram variações positivas nos meses de janeiro, maio, junho, julho e dezembro, tendo média igual a 9,$9 ; 6,1 ; 15,6 ; 29,0$ e $2,9 \mathrm{~mm}$, respectivamente. Os meses de fevereiro, março, abril, agosto, setembro, outubro e novembro obtiveram variações negativas, em média, $-2,1,-20,0,-2,6,-14,6,-1,1,-12,3,-8,8$ $\mathrm{mm}$, respectivamente (Figura 6). 


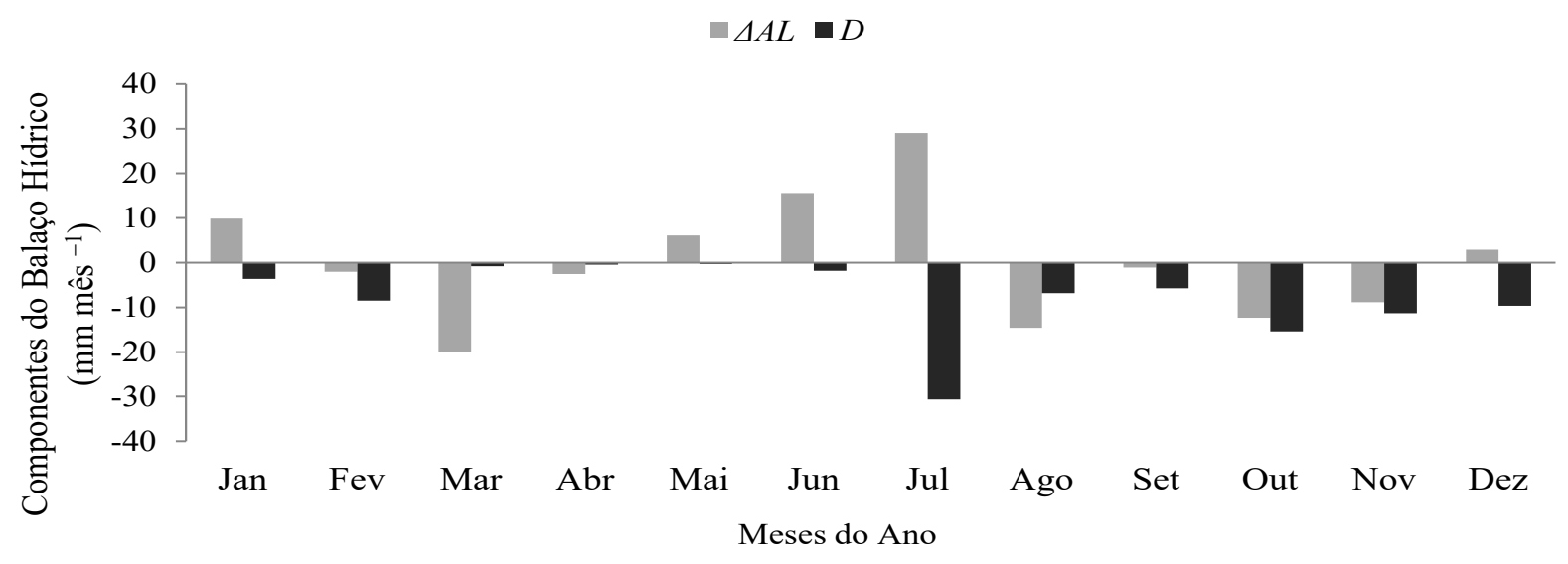

FIGURA 6: Variação do armazenamento de água no solo $\left(\Delta A_{L}\right)$ e drenagem interna $(D)$ verificada em um Latossolo Vermelho-Amarelo, sob Floresta Nativa, entre janeiro e dezembro de 2009, em Telêmaco Borba - PR.

FIGURE 6: Variation of soil water storage $\left(\Delta A_{L}\right)$ and internal drainage $(D)$ verified in an Oxisol, under Native Forest, between January and December 2009, in Telêmaco Borba - PR state.

A $D$ foi maior em julho $\left(30,6 \mathrm{~mm}^{\mathrm{mês}}{ }^{-1}\right)$, seguido por outubro $\left(15,4 \mathrm{~mm}\right.$ mês $\left.{ }^{-1}\right)$, novembro $(11,3$ $\mathrm{mm}$ mês $^{-1}$ ). O valor total anual da drenagem interna foi, em média, de $94,9 \mathrm{~mm}$ ano ${ }^{-1}$ (Figura 6). Nos meses de fevereiro, julho, outubro e dezembro, ocorreram os maiores valores de $P$ (Figura 4), tendo $D$ de 8,$5 ; 30,6$; 15,4 e 9,6 $\mathrm{mm}^{\text {mês }}{ }^{-1}$, respectivamente.

\section{CONCLUSÕES}

Os valores de massa específica, micro, macro e porosidade total do solo obtidos no experimento se enquadraram nas faixas consideradas adequadas para solos de textura arenosa. O Latossolo VermelhoAmarelo apresenta alta condutividade hidráulica $\left(K_{0}\right)$, característica de solos bem drenados, devido à alta porosidade.

A floresta nativa não sofreu limitações quanto à aeração, pois valores abaixo do limite crítico não foram atingidos ao longo do ano.

Nenhum dos meses do ano atingiu o armazenamento de água no solo no ponto de murcha permanente.

A drenagem interna média é maior nos meses com maior precipitação, sendo o valor total anual médio de $94,9 \mathrm{~mm} \mathrm{ano}^{-1}$.

O valor médio da $E R$ ocorrida foi de $1355,9 \mathrm{~mm} \mathrm{ano}^{-1}$, média de $3,7 \mathrm{~mm} \mathrm{dia}^{-1}$. Os maiores valores de $E R$ ocorrem nos meses mais chuvosos.

\section{REFERÊNCIAS}

ALMEIDA, A. C.; SOARES, J. V. Comparação entre uso de água em plantações de Eucalyptus grandis e floresta ombrófila densa (Mata Atlântica) na costa leste do Brasil. Revista Árvore, Viçosa, MG, v. 27, n. 2, p. 159-170, 2003.

ANTONINO, A. C. D. et al. Balanço hídrico em solo com cultivo de subsistência no semi-árido do nordeste do Brasil. Revista Brasileira de Engenharia Agrícola e Ambiental, Campina Grande, v. 4, p. 29-34, 2000. ARAUJO, M. A.; TORMENA, C. A.; SILVAA. P. Propriedades físicas de um Latossolo Vermelho Distrófico cultivado e sob mata nativa. Revista Brasileira de Ciência do Solo, Viçosa, MG, v. 28, p. 337-345, 2004. ASSIS, R. L.; LANCAS, K. P. Avaliação dos atributos físicos de um Nitossolo Vermelho distroférrico sob sistema plantio direto, preparo convencional e mata nativa. Revista Brasileira Ciência Solo, Viçosa, MG, v. 29, n. 4, p. 515-522, 2005.

AUBRÉVILle, A. A floresta de pinho do Brasil. Rio de Janeiro: Anuário Brasileiro de Economia, 1949. BACKES, A. Dinâmica do pinheiro brasileiro. Iheringia. Série Botânica, Porto Alegre, v. 30, p. 49-84, 1999. 
BRUN, E. J. Matéria orgânica do solo em plantios de Pinus taeda e $P$. elliottii em duas regiões do Rio Grande do Sul. 2008. 118 f. Tese (Doutorado) - Universidade Federal de Santa Maria, 2008.

CAVALCANTE, E. P.; PRADO, H. Ambientes de produção de cana-de-açúcar de Latossolos da região de Araxá - MG. Nucleus, Ituverava, v. 7, p. 115-124, 2010.

CAVICHIOLO, S. R. Perdas de solo e nutrientes por erosão hídrica em diferentes métodos de preparo do solo em plantio de Pinus taeda. 2005. 152 f. Tese (Doutorado) - Universidade Federal do Paraná, Curitiba, 2005.

CAVIGLIONE, J. H. et al. Cartas climáticas do Paraná. Londrina: IAPAR, 2000. Disponível em: <http:// www.iapar.br/modules/conteudo/conteudo.php?conteudo=677>. Acesso em: 18 jan. 2012.

CESTARO, L. A. Estudo microclimático do interior de uma mata de araucária na Estação Ecológica de Aracuri, Esmeralda, RS. Revista Árvore, Viçosa, MG, v. 12, p. 41-57, 1988.

COOTE, D. R.; RAMSEY, J. F. Quantification of the effects of overs 35 years of intensive cultivation on four soils. Canadian Journal of Soil Science, Birmingham, v. 63, p. 1-14, 1983.

CURTIS, R. O.; POST, B. W. Estimating bulk density from organic matter content in some Vermont forest soils. Soil Science Society of America Proceedings, New York, v. 28, p. 285-286, 1964.

DALBIANCO, L. Variabilidade espacial e estimativa da condutividade hidráulica e caracterização físico-hídrica de uma microbacia hidrográfica rural. 2009. 116 f. Dissertação (Mestrado) - Universidade Federal de Santa Maria, 2009.

DEDECEK, R. A. et al. Influência do sítio no desenvolvimento do Pinus taeda aos 22 anos: 1. Características físico-hídricas e química do solo. Floresta, Curitiba, v. 38, p. 507-416, 2008.

DOURADO NETO, D. et al. Software to model soil water retention curves (SWRC, version 2.00). Scientia Agricola, Piracicaba, v. 57, p. 191-192, 2001.

EMBRAPA. Manual de métodos de análise de solo. Rio de Janeiro: EMBRAPA Solos, 2011.

EMBRAPA. Sistema Brasileiro de Classificação de Solos. Brasília: EMBRAPA, 2013.

ERICKSON, A. E. Tillage effects on soil aeration. In: PREDICTING TILLAGE EFFECTS ON SOIL PHYSICAL PROPERTIES AND PROCESSES, 1982, Madison. Proceedings... [s. 1.]: American Society of Agronomy, 1982. p. 91-104.

GODEFROY, J.; JACQUIN, F. Relation entre la stabilité structurale des sols cultivés et le apports organiques en conditions tropicales; comparasion avec les sols forestiers. Fruits, Les Ulis, v. 30, p. 595-612, 1975.

HAJABBASI, M. A.; JALALIAN, A.; KARIMZADEH, H. R. Deforestation effects on soil physical and chemical properties, Plant Soil, New York, v. 190, p. 301-308, 1997.

HAMBLIN, A. P. The influence of soil structure on water movement, crop root growth and water uptake. Advances in Agronomy, Delaware, v. 38, p. 95-158, 1985.

HIGUCHI, P. et al. Partição espacial de espécies arbóreas em função da drenagem do solo em um fragmento de floresta com araucária no sul do Brasil. Ciência Florestal, Santa Maria, v. 24, n. 2, p. 421-429, 2014.

HUECK, K. As florestas da América do Sul: ecologia, composição e importância econômica. São Paulo: Polígono, 1972. $466 \mathrm{p}$.

ISERNHAGEN, I. A fitossociologia florestal no Paraná e os programas de recuperação de áreas degradadas: uma avaliação. 2001. Dissertação (Mestrado) - Universidade Federal do Paraná, Curitiba, 2001.

KIEHL, E. J. Manual de edafologia. São Paulo: Agronômica Ceres, 1979. 262 p.

KLEIN, R. M. O aspecto dinâmico do pinheiro brasileiro. Selowia, Itajaí, n. 12, p. 17-44, 1960.

LETEY, J. Relationship between soil physical properties and crop production. Advances Soil Science, New York, v. 1, p. 277-294, 1985.

LIMA, J. R. S. et al. Balanço hídrico no solo cultivado com feijão caupi. Revista Brasileira de Ciências Agrárias, Recife, v. 1, p. 89-95, 2006.

MELLONI, R. et al. Avaliação da qualidade de solos sob diferentes coberturas florestais e de pastagem no sul de Minas Gerais. Revista Brasileira Ciência do Solo, Viçosa, MG, v. 32, p. 2461-2470, 2008.

MORI, H. F. et al. Perda de água, solo e fósforo com aplicação de dejeto líquido bovino em Latossolo sob plantio direto e com chuva simulada. Revista Brasileira de Ciência do Solo, Viçosa, MG, v. 33, p. 189198, 2009.

MUALEM, Y. A new model for predicting the hydraulic conductivity of unsaturated porous media. 
Water Resources Research, Washington, v. 12, p. 513-522, 1976.

PACHECHENIK, P. E. Demanda hídrica em plantio de pinus e em uma floresta nativa, na região de Telêmaco Borba. 2010. 111 f. Tese (Doutorado) - Universidade Federal do Paraná, Curitiba, 2010.

PINTO, D. B. F. Aplicação do modelo SWAT (Soil and Water Assessment Tool) na simulação hidrossedimentológica em bacia hidrográfica da Serra da Mantiqueira, MG. 2011. Tese (Doutorado) Universidade Federal de Lavras, Lavras, 2011.

PREVEDELLO, C. L. Física do solo com problemas resolvidos. Curitiba: Sociedade autônoma de estudos avançados em Física do Solo, 1996. 446 p.

PORTUGAL, A. F.; COSTA, O. D. V.; COSTA, L .M. Propriedades físicas e químicas do solo em áreas com sistemas produtivos e mata mineira. Revista Brasileira de Ciência do Solo, Viçosa, MG, v. 34, p. 575-585, 2010.

REICHARDT, K.; TIMM, L. C. Solo, planta e atmosfera: conceitos, processos e aplicações. Barueri: Manole, 2012. $500 \mathrm{p}$.

SEITZ, R. A. Estudo da variação da radiação solar, temperatura e umidade relativa do ar no interior de uma mata de Araucaria angustifolia em relação ao terreno livre. Floresta, Curitiba, v. 7, p. 36-45, 1976.

SILVA, D. C. et al. Atributos do solo em sistemas agroflorestais, cultivo convencional e floresta nativa. REA - Revista de estudos ambientais, Blumenau, v. 13, n. 1, p. 77-86, 2011.

SILVA, G. J. et al. Variação de atributos físico-hídricos em Latossolo Vermelho Amarelo do cerrado matogrossense sob diferentes formas de uso. Revista Brasileira de Ciência do Solo, Viçosa, MG, v. 32, p. 2135-2143, 2008.

SILVA, M. A. S. et al. Atributos físicos do solo relacionados ao armazenamento de água em um Argissolo Vermelho sob diferentes sistemas de preparo. Ciência Rural, Santa Maria, v. 35, p. 544-552, 2005.

SOARES, J. V.; ALMEIDA A. C.; PENCHEL R. M. Balanço hídrico de plantações de eucalipto a partir da estimativa de transpiração pelo método de Penman-Monteith. In: CONFERENCE ON SILVICULTURE AND IMPROVEMENT OF EUCALYPTUS, 1997, Salvador. Anais... Salvador: International Union of Forest Research Organizations, 1997. p. 52-61.

VAN GENUCHTEN, M. T. A closed-form equation for predicting the hydraulic conductivity of unsaturated soil. Soil Science Society America Journal, New York, v. 44, p. 892-898, 1980.

VIANA, E. T. et al. Atributos físicos e carbono orgânico em latossolo vermelho sob diferentes sistemas de uso e manejo. Revista Brasileira Ciência do Solo, Viçosa, MG, v. 35, n. 6, 2011. 